\title{
Going Underground: Fatigue and Sleepiness in Tunnelling Operations
}

\author{
Sally Maynard ${ }^{1}$, Wendy Jones ${ }^{2}$, Ashleigh Filtness ${ }^{1}$, Alistair Gibb², Roger Haslam ${ }^{3}$ \\ ${ }^{1}$ Transport Safety Research Centre, School of Design and Creative Arts, Loughborough University, \\ Loughborough LE11 $3 T U$ \\ ${ }^{2}$ School of Architecture, Building and Civil Engineering, Loughborough University, Loughborough LE11 $3 T U$ \\ ${ }^{3}$ School of Design and Creative Arts, Loughborough University, Loughborough LE11 3TU
}

Corresponding author: Dr Sally Maynard, s.e.maynard@lboro.ac.uk

Keywords: fatigue; shift work; construction industry; safety; sleep; sleepiness

\begin{abstract}
This research represents one of the first qualitative studies to investigate fatigue in the tunnelling sector of the construction industry. It explores the opinions of tunnellers and their managers about how fatigue influences or is influenced by tunnelling, and how this is managed. Fatigue and sleepiness were discussed in six focus groups with frontline workers $(n=42)$ and 10 manager interviews. Fatigue was seen to be a problem, with all participants having experienced, or recognised in others, the feeling of sleepiness whilst at work. Fatigue and sleepiness are not commonly discussed between tunnelling workers and they do not feel comfortable reporting instances of fatigue. The research shows that workers in the tunnelling construction sector are exposed to a wide range of occupational factors that potentially increase their vulnerability to fatigue, including the physical environment, repetitive and monotonous tasks, variable shift patterns and manual work. Additionally, personal factors such as social and family demands, long commute times and living away from home, can increase the risk of fatigue. The construction industry in general has gone some way to address fatigue and there is opportunity to further improve fatigue management. However, a major shift is needed before workers will feel able to openly discuss fatigue with their employer.
\end{abstract}

\section{INTRODUCTION}

The personal consequences of working in general construction have been acknowledged by Sherratt and Turner (2018), who note that "construction work is unhealthy and bad for worker wellbeing. The industry structure results in insecure contracts, transient work, long working hours, stressful workplaces and poor occupational health" (p 283). In particular, the negative impact of fatigue and sleepiness on general safe operations across many industries is widely acknowledged (Gander et al., 2011) and there is currently no reason to believe that the tunnelling sector, a type of construction, is any different. Sleepy individuals exhibit impaired performance at a range of cognitive abilities, particularly higher order executive functions which engage the prefrontal cortex (Kilgore, 2010). This reduced ability, for example in decision making and ability to update strategies based on new information, can have serious consequences in safety critical situations (Whitney et al., 2015). Furthermore, fatigue and sleepiness pose unique issues for occupational safety and health (OSH) management, as they are influenced by both work-related and non-work-related factors (Gander et al., 2011).

It should be noted here that this research recognises that there is a difference between fatigue and sleepiness and both concepts were the focus throughout the research. As noted by PilkingtonCheney et al. (2020), sleepiness is considered to result from insufficient sleep or circadian time of 
day, whereas fatigue is more broadly considered as resulting from work and task related activities. Relevant for this study is the fact that, in occupational settings, sleepiness and fatigue are often used interchangeably. Within the current work a single investigation is undertaken to investigate fatigue, while recognising that some aspects relate directly to sleepiness. This broad usage of the term fatigue to include sleepiness was employed during the data gathering.

Most published research into fatigue is focused on transport or medical personnel (see, for example, Filtness \& Naweed, 2017; Anderson et al., 2012; Anund et al., 2018; Ku \& Smith, 2010). Previous research which has examined fatigue in construction workers is more limited, relating largely to physical fatigue (see, for example, Maiti, 2008; Chang et al., 2009; Maman et al., 2017). Where studies have examined fatigue in the context of the psychosocial work environment, this has been in connection with specific trades such as bricklayers (see, for example, Boschman et al., 2013 and Zhang et al., 2015). An exception can be seen in Jackson et al. (2013) employed 20 interviews and a survey $(n=47)$ to find that worker and manager fatigue is a problem on rapid renewal highway construction sites and that it is exacerbated by construction practices such as night working. Notably, the existence of fatigue was widely acknowledged by both management and labour. The study found that methods employed for dealing with fatigue were informal; a wide variability in attitudes relating to fatigue was also found.

Research relating to the wider construction industry is of relevance to this research. For example, with regard to the issue of fatigue in the conflict between work and family life in construction workers, Bowen et al (2018) investigated the situation of South African construction professionals, examining the relationship between work contact, work-family conflict and consequent outcomes of psychological distress and sleep problems. Via an integrated model of these factors, the authors found that sleep problems are influenced by work-family conflict, work contact and psychological distress. Holguín-Veras et al. (2003) carried out field surveys and interviewed 30 construction employees working at night and found ample evidence that this kind of work has negative impacts on workers' sleep patterns, body rhythms and social and family lives.

Dong (2005) aimed to examine work scheduling in the construction industry and to investigate whether there is a connection between workhours and safety outcomes among the workers in the industry. The study found that construction workers experience long workhours and irregular work schedules which have an adverse effect on worker safety. Such extreme working conditions were investigated by Kumar and Chaturvedi (2018) in relation to the relatively small number of female employees in the construction industry; this research attempts to examine the challenges associated with maintaining work-life balance in the construction industry, specifically in relation to the associated under-representation of women. They concluded that work-life balance is equally important for the individual and the organisation.

Relatively little research has been conducted in tunnelling construction, particularly relating to the issue of fatigue. Workers in the tunnelling sector, however, are particularly vulnerable to fatigue due to the use of shift working (which is less common elsewhere in general construction work) and its associated impact on sleeping patterns. Bustamante (2016) used a range of methods including actigraphy and reported that many tunnelling workers slept less than six hours between shifts, slept less when working night rather than day shifts, and that this had an adverse impact on cognitive performance. There is evidence from research with miners that "restricted sleep and quick shiftchange periods may lead to long-term sleep loss and associated fatigue" (Paech et al., 2010) and that fatigue is associated with an increase in occupational accidents (Paech et al., 2010). 
Studies by Karkoulias et al. (2012) and Lykouras et al. (2014) both recognise that working shifts leads to diminished time for sleeping and increased sleepiness and can be dangerous particularly in large scale construction, such as tunnels. Karkoulias et al.'s (2012) study of 42 male tunnelling workers examined whether sleep duration and daytime sleepiness differed between day and night shifts among these workers. They concluded that rotating shifts (as often found in tunnel construction) do not contribute significantly to daytime sleepiness. Lykouras et al. (2014) involved 44 tunnelling construction workers ( 42 male and 2 female) in their study which attempted to evaluate the impact of shifts on sleepiness and correlate sleepiness scores (ESS) (Johns, 1991) to the experience in a shift schedule. They concluded that workers who had been employed in the industry for a longer time had lower levels of sleepiness. However, they found no relationship between night shifts and sleepiness, which they related to workers' exposure to artificial lighting in the construction site.

Tunnellers have a specific skill set and way of working which sets them apart from workers within generic construction work, for example, it is very common for tunnelling construction to operate $24 / 7$. This brings additional pressures in the process, which are less commonly experienced by the wider construction industry, for example, working in established small teams and travelling to remote locations to work for intense period before moving on to another worksite. Forberg et al. (2010) found that a small group of tunnelling workers living in an isolated environment adapted relatively easily to shift changes in the absence of family responsibilities. However, most tunnellers still have everyday commitments even if they are living away from family, and they also face additional risks from commuting long distances between blocks of shifts (Jones et al., 2019).

Other key differences between tunnelling and construction and other general shiftwork include light exposure (including circadian rhythm as well as illumination), atmospheric pressure/decompression sickness (DCS), oxygenation/ventilation, physical work environment (e.g. noise and heat) and utilisation of powered haulage in small areas. Furthermore, DCS is worth mentioning as an occupational exposure unique to tunnelling (and a very limited number of other industries) of which fatigue can be a symptom (Francis \& Mitchell, 2003). Additional impacts can arise from the poor diet and limited opportunity to exercise which are common in general construction work, particularly where working hours are long and time with family is limited (e.g. Lingard and Turner, 2017).

Further investigation within the specific context of tunnelling construction is needed to understand the causes and consequences of fatigue and sleepiness in these operations. As mentioned previously, fatigue and sleepiness are different concepts; fatigue includes the inability to continue or the impairment of performance at an activity because it has been going on too long (Bartley and Chute, 1947) whereas sleepiness is defined as a physiological urge to fall asleep resulting from sleep loss or circadian effects (Dement and Carskadon, 1982). The overall aim of this work was to improve the general construction industry's understanding of the prevalence of fatigue and sleepiness within 24-hour operations using tunnelling as a case study. Furthermore, the work aims to investigate how fatigue and sleepiness relate to shift work patterns and non-work activities, and how the industry can better manage the risks involved.

Focus groups and interviews were used to investigate the personal experiences and opinions of tunnelling workers and managers relating to fatigue and thus to surface the hidden knowledge of these industry experts. It is particularly valuable to obtain the opinions of the workforce themselves since their day-to-day experiences can provide realistic and detailed data on the subject. The main tasks being undertaken by the participants were sinking shafts ready to commence tunnelling, operating the tunnel boring machines (TBMs) and managing 'muck away' - removing the excavated 
material from the newly dug tunnel. The focus groups and interviews addressed the following research questions:

- Do tunnelling personnel believe fatigue/sleepiness to be a problem in their sector?

- What are the causes and consequences of fatigue/sleepiness in the tunnelling sector?

- How is fatigue/sleepiness managed in the tunnelling sector?

\section{METHOD}

Six focus groups with frontline workers and 10 manager interviews were conducted with employees working on a tunnelling construction mega project in the UK. The participants were working at four different sites which were at varying stages of development. Three of the sites were operating 24hour working. At least one focus group and two interviews were carried out at each of the four sites. Several shift patterns were discussed during this research; some of these are common through the industry, others were developed specifically to meet the requirements of this project.

The study was carried out in accordance with Loughborough University's Code of Practice for Research as administered by its Ethical Sub-Committee.

\subsection{Focus groups}

Discussion groups were conducted with frontline workers who had experience of 24 hour working to explore their experiences of sleepiness/fatigue in tunnelling and other construction activities: what affects it, how they manage it, what effects it has, and whether there are other impacts of shift patterns. A structured guide was used to ensure consistency across all of the groups. Table 1 shows examples of the questions which were included in the guide. At the beginning of each focus group the concept of 'fatigue' was discussed in order to be sure that participants were aware of its meaning, but at the same time researchers attempted not to restrict their thoughts by enforcing constricting definitions. The project definition focused the discussion and was as follows: 'a psychological and/or physical impairment experienced by a driver which has the potential to reduce optimal performance. Fatigue is considered to be multifaceted, encompassing pressures from both the sleepiness related to human biology and task related fatigue. So it may be: 1) Sleepiness due to insufficient sleep and/or time of day, or 2) Task related fatigue due to the nature of tunnelling construction resulting in an inability to continue or impairment in performance caused by time on task due to the same activity going on too long; overload of cognitive demands during times of exposure to demanding workload or underload of cognitive demands during times of monotonous activity. Physical muscle fatigue due to physical exertion, for example, operating heavy machinery'. The focus groups were facilitated by either one or two researchers, with one specific researcher attending all of the groups. They were audio recorded (with the permission of participants) and lasted around 60 minutes.

\subsection{Manager interviews}

One-to-one interviews were conducted with managers $(n=10)$; two by telephone and the remainder face-to-face. The interviews lasted 30-45 minutes and were audio recorded, with the permission of the interviewees. The manager interviews were completed in parallel with the focus groups to get a broader range of data and provide a complementary perspective to what was said by the workers, identifying similarities as well as differences. A list of questions guided the interviews to ensure 
consistency across all of the interviews. Table 1 shows examples of the questions which were asked of the participants.

\begin{tabular}{|c|c|c|}
\hline Topic & Example question - focus group & Example question - interview \\
\hline Does fatigue occur? & $\begin{array}{l}\text { Have you ever felt tired while } \\
\text { working, or know anyone that has? } \\
\text { What was this like? How did it affect } \\
\text { your work? }\end{array}$ & $\begin{array}{l}\text { Do you think fatigue/sleepiness is } \\
\text { a problem in your industry? }\end{array}$ \\
\hline Consequences of fatigue & $\begin{array}{l}\text { How is your work affected when you } \\
\text { feel tired? }\end{array}$ & $\begin{array}{l}\text { Do you think fatigue/sleepiness } \\
\text { influences safety/productivity at } \\
\text { work? }\end{array}$ \\
\hline $\begin{array}{l}\text { Strategies for managing } \\
\text { fatigue }\end{array}$ & $\begin{array}{l}\text { What do you do if you feel } \\
\text { fatigued/sleepy at work? If you } \\
\text { notice someone at work is sleepy } \\
\text { what would you do? }\end{array}$ & $\begin{array}{l}\text { What do you believe the industry } \\
\text { is doing well in the management } \\
\text { of fatigue/sleepiness? }\end{array}$ \\
\hline Causes of fatigue & $\begin{array}{l}\text { What might cause you to be fatigued } \\
\text { at work? Does the physical } \\
\text { environment influence fatigue, e.g. } \\
\text { excessive heat, humidity, lighting? }\end{array}$ & $\begin{array}{l}\text { What do you think causes workers } \\
\text { in your industry to be fatigued at } \\
\text { work? }\end{array}$ \\
\hline Workplace & $\begin{array}{l}\text { Would you tell your supervisor if you } \\
\text { were fatigued/sleepy whilst at work? }\end{array}$ & $\begin{array}{l}\text { What do you do if one of your } \\
\text { team reports they are tired at } \\
\text { work (before and after exceeding } \\
\text { shift limits)? }\end{array}$ \\
\hline $\begin{array}{l}\text { Barriers to fatigue } \\
\text { management }\end{array}$ & $\begin{array}{l}\text { Do you experience pressure to reach } \\
\text { production targets? Can this cause } \\
\text { fatigue? }\end{array}$ & \\
\hline Shift patterns and overtime & $\begin{array}{l}\text { What shift patterns are you } \\
\text { working? Is that what you usually } \\
\text { work/have worked before? Do you } \\
\text { ever informally end up working } \\
\text { overtime e.g. staying past the end of } \\
\text { your shift? Does this influence your } \\
\text { fatigue? }\end{array}$ & $\begin{array}{l}\text { Are shift patterns fixed? Do you } \\
\text { allow your workers to swap } \\
\text { shifts? } \\
\text { How much extra overtime can } \\
\text { workers pick up? }\end{array}$ \\
\hline Time spent outside work & $\begin{array}{l}\text { How does your non-work time } \\
\text { (including commute) influence how } \\
\text { fatigued/sleepy you feel? What } \\
\text { factors influence how much you } \\
\text { would sleep when not at work - } \\
\text { when in digs, when at home? Can } \\
\text { you switch off and relax at the end } \\
\text { of the day after work? }\end{array}$ & \\
\hline
\end{tabular}

Table 1: Overview of focus group and management questions

\subsection{Analysis}

Analysis was carried out using NVivo (ver 12.0) software and by a team of four researchers. The dialogue from each focus group was transcribed verbatim, de-identified and coded in two stages of 
qualitative thematic data analysis: (1) open coding and (2) axial coding (Saldana, 2009). Given the size and richness of the dataset, these two stages of analysis created a robust process, ensuring all data were captured and considered during analysis.

The first stage (open coding) identified units of information that addressed the research aims. This was a bottom-up approach to obtain first impressions from the transcripts and was led by the opinions of the participants. During this stage, two researchers (who had either attended the focus groups or were well acquainted with the transcripts) read through the data and started to create tentative labels for chunks of data that summarised the ideas arising from the data. The two researchers separately coded the transcript from the first completed focus group in this way and then met to compare their analysis using 'coding stripes' in the NVivo software and subsequently to refine and agree their final set of codes.

In the second stage (axial coding), relationships were identified among the open codes; these resonated with pre-established constructs derived from fatigue risk management theory and the tunnelling construction context and the core themes were subsequently identified. This axial coding was a critical step for relating categories and concepts with one another and refining the categories. This resulted in an agreed set of 24 codes (or nodes as they are described in NVivo); these were rationalised by comparing and contrasting the nodes derived by the two researchers during their initial analysis and ensuring that all of the topics raised were covered by the new codified group. The 24 codes were then used to analyse the remainder of the focus groups - each discussion was analysed by one of the research team (a total of four individuals).

The data from the managers was included in order to contextualise the focus group data and the same 24 codes were subsequently used to analyse the manager interviews; no additional codes were identified during the analysis. One of the original two researchers undertook this additional analysis and the consistency in use of themes between the two work roles ensured a common context.

\section{RESULTS}

Six focus groups were conducted and involved 42 participants; the highest proportion were in the age range $45-54$ years (31\%); the remainder were as follows: $18-24$ years (3\%), $25-34$ years (23\%), $35-44$ years (20\%) and $55-64$ years (23\%). They had an average of 12 years and three months' experience in tunnelling construction. Participants had a mix of trades backgrounds: some were miners or had other tunnelling-specific job roles such as grouting or responsibility for 'muck away'; others had roles such as mechanic, electrician, welder, slinger, but were performing these roles in a tunnelling context.

The ten managers interviewed were from the same four sites as the focus groups. All had experience of supervising tunnelling workers in 24-hour working and were either currently responsible for shift workers on this project or would be responsible for them shortly. Some came from engineering backgrounds and had job titles including Section Engineer, Site Engineer and Project Manager. The remainder had been promoted from frontline work to roles including General Foreman and TBM Superintendent. Their range of experience in tunnelling construction was between three and 45 years; seven had at least ten years' experience in the sector.

See Table 2 for demographic information relating to the participants and details relevant to the locations at which they were held. 


\begin{tabular}{|c|c|c|c|c|c|c|}
\hline Location & $\begin{array}{l}\text { No. of } \\
\text { focus } \\
\text { groups }\end{array}$ & $\begin{array}{l}\text { No. of } \\
\text { interviews }\end{array}$ & Shift schedule & Nature of site & $\begin{array}{l}\text { No. of } \\
\text { participants }\end{array}$ & $\begin{array}{l}\text { Median } \\
\text { tunnelling } \\
\text { tenure }\end{array}$ \\
\hline $\begin{array}{l}\text { L1 } \\
\text { Site } 1\end{array}$ & Group 1 & 2 & $\begin{array}{l}\text { 7-2 7-2 7-3: } 8 \\
\text { hours work } \\
\text { time (up to } 10 \\
\text { hours on site to } \\
\text { allow for } \\
\text { briefings and } \\
\text { handover) }\end{array}$ & $\begin{array}{l}\text { This was a large } \\
\text { site where work } \\
\text { was focussed on } \\
\text { constructing the } \\
\text { shaft prior to } \\
\text { commencing } \\
\text { tunnelling }\end{array}$ & 7 & 11.0 years \\
\hline $\begin{array}{l}\text { L2 } \\
\text { Site } 2\end{array}$ & Group 2 & $\begin{array}{l}2 \\
\text { (telephone) }\end{array}$ & $\begin{array}{l}\text { 5-2 4-3 (11- } \\
\text { hour shifts, } \\
\text { non- } \\
\text { continuous) }\end{array}$ & $\begin{array}{l}\text { This was a smaller } \\
\text { site where } \\
\text { tunnelling was } \\
\text { underway }\end{array}$ & 7 & 14.5 years \\
\hline \multirow{3}{*}{$\begin{array}{l}\text { L3 } \\
\text { Site } 3\end{array}$} & Group 3 & \multirow{3}{*}{3} & \multirow{3}{*}{$\begin{array}{l}7-27-27-3 \text { as } \\
\text { on site } 1\end{array}$} & \multirow{3}{*}{$\begin{array}{l}\text { This was a large } \\
\text { site where } \\
\text { tunnelling was } \\
\text { underway }\end{array}$} & 8 & 11.0 years \\
\hline & Group 4 & & & & 7 & 20.0 years \\
\hline & Group 5 & & & & 6 & 5.4 years \\
\hline $\begin{array}{l}\text { L4 } \\
\text { Site } 4\end{array}$ & Group 6 & 3 & $\begin{array}{l}5 \text { days, 10- hour } \\
\text { shift }\end{array}$ & $\begin{array}{l}\text { This was a large } \\
\text { site which was } \\
\text { preparing for } \\
\text { tunnelling }\end{array}$ & 7 & $\begin{array}{l}\text { Not } \\
\text { available }\end{array}$ \\
\hline TOTAL & 6 & 10 & & & 42 & $11.0^{*}$ \\
\hline
\end{tabular}

Table 2: Overview of demographic and other details relating to focus groups and interviews

As Table 2 shows, three shift patterns were in use on the sites where the research took place. However, discussions in focus groups and interviews were broad, and considered many different patterns that participants had worked throughout their tunnelling careers. Historically, tunnelling construction has operated a '7-3 7-4' pattern: seven consecutive twelve-hour nightshifts, followed by three days off; then seven consecutive twelve-hour day shifts followed by four days off. This allows a long break over a weekend every three weeks to travel home to family for those living away. It has a working week which averages 57.2 hours. In recent years construction projects (including the one studied in this research) have introduced other patterns in a bid to reduce fatigue risk. These include '7-2 7-2 7-3: an eight-hour shift pattern, workers do 7 back (evening) shifts, two days off, seven day shifts, two days off, seven night shifts, three days off. Time to travel home for those living away is only once every four weekends and is for a short time only. This shift pattern often has 'backward' rotating shifts which are generally recognised as harder to adapt to than forward rotating shifts. It has a working week which averages 53 hours. A third common pattern is '5-2': sites which choose to close down over the weekend might have a 12-hour pattern over five days and nights.

On some sites, managers and supervisors worked similar hours to the frontline workers, on others they worked a variety of patterns to allow handovers and consistency. Those in more senior or specialist roles generally worked regular day shifts but were on call at other times. 
The six key findings which were discussed in detail in both the focus groups and manager interviews will be considered below. These findings have been selected as those which relate directly to fatigue and which were most often raised by the participants. They are also significantly relevant and particular to tunnelling construction - a field in which 24/7 working necessitates shifts and in which workers often live away from their families for significant periods. They reflect participants' experiences relating to tunnelling shift work throughout their careers, not just on this project. The results are therefore considered as being from a single cohort rather than breaking them down by current work site/shift pattern.

\subsection{Nature and presence of fatigue}

The results in this section include findings assigned to the following codes:

- definitions and understanding of fatigue

- other effects of shiftwork

- reporting or admitting fatigue

- sleep, lack of sleep and time awake

The research revealed that fatigue is a significant problem for the participants; that the management is not yet adequately addressing it; and that no single easy solution exists for reducing it. The significant presence of fatigue was widely recognised, although there was variation in opinions about the scale of the problem.

Fatigue in tunnelling construction was seen as multifaceted, taking in pressures both from sleepiness (due to insufficient sleep and/or time of day) and task-related fatigue (due to the nature of tunnelling construction and allied work carried out in a particular physical environment). Participants in both the focus groups and interviews were aware of different types of fatigue including different implications for the mind and the body, and how these relate to each other. As one focus group participant noted: "Yeah, tiredness, and run down, physically, body wise and all that, mentally as well". Physical fatigue is problematic due to the nature of the job, and workers recognised experiencing psychological and cognitive impacts of fatigue in being miserable, 'snappy' and having no energy to give attention to their children. The managers suggested this might lead to being unable to think, becoming inefficient, or being 'exhausted'.

Individual differences between workers are of importance when considering fatigue, with some people preferring particular or specific shifts and working times (e.g. constant night shifts). Fatigue manifests to workers in a lack of concentration, a feeling of switching off or working on automatic, their whole body feeling tired, and the experience of making more mistakes. This can be caused by the repetitive nature of many of the workers' tasks and usually happens most markedly during the latter of their shifts - in this case the sixth in a series of seven 12-hour periods. One worker described this as being "tired when you're getting up". Constant concentration helps workers not to feel fatigued, and they suggested that when they are least occupied, they switch off and feel tired. They reported that being busy makes the shift pass more quickly for them and may combat feeling tired.

For the managers, fatigue manifested via long hours when on shift or when working on 'days', which tended to last longer than the standard eight hours. They commented that working a greater number of days during the month due to being on call or having variable workloads leads to flexible working hours. The managers also reported being expected to answer e-mails at the weekend when 
they are not working and when covering 24-hour working. As noted by one manager: "you take a lot of work home with you as a manager in order to keep the job running. This is the hidden fatigue. I have worked till past midnight twice already this week to keep up with the workload." One manager who worked away from their home base also admitted working straight through (seven days of the week) until returning to their family.

\subsection{Key contributors to fatigue}

The results in this section include findings assigned to the following codes:

- commuting - day-to-day

- commuting - home after several shifts

- other effects of shiftwork

- physical environment

- shift patterns - effects of different ones

- shift patterns - times and situations that are the most fatiguing

- $\quad$ shift patterns - working weekends

- what makes shifts longer

- work life home life

Study participants recognised the contributing factors to fatigue to be wide and at times complex. The key contributors to fatigue were reported to be:

- Inability to get sufficient sleep

- The physical nature of tunnelling work

- The physical environment - working in a tunnel means that some workers rarely experience the daylight, exacerbated by shift patterns. It can also be very hot and humid, becoming warmer the further into the tunnel the workers are. This is caused by both the machines and the concrete which is being worked. The machines are also noisy

- The repetitive (or monotonous) nature of tunnelling work

- Long commuting times added to shift periods

- Long shifts which lead workers to feel they only have time to work; some reported having to drink coffee to stay awake to get home, then drink alcohol to get to sleep

- Rotating shifts which continuously disturb their body clock

- Long stretches of shifts, e.g. 7-3 7-4, which comprises seven consecutive twelve-hour nightshifts, followed by three days off; then seven consecutive twelve-hour day shifts followed by four days off

\subsection{Commuting}

The results in this section include findings assigned to the following codes:

- commuting - day-to-day

- commuting - home after several shifts

- other effects of shiftwork

- work life home life 
As noted above, long commuting times were a particular issue for the focus group participants and managers, which suggests it merits further discussion. Notably, many participants (including managers) knew workers who lived a long distance from their work site. Commuting times of up to two hours each way were mentioned. Those who lived further away than this were likely to have temporary accommodation, but even this may be located far from the site (for example in cheaper areas of the city). This added to commuting times for certain workers, a concern voiced by the managers. These long periods of time spent travelling to work were clearly a cause of fatigue, as they added to the hours workers were awake: "Then you're trying to stay awake on the train on the way home, so you don't miss your stop. I can end up anywhere literally, and I have done, miles away ... it literally only happened a couple of weeks ago". Twelve-hour shifts cause a particular problem, with workers potentially leaving their house at 4.00-4.30 am and not returning home until $9.00 \mathrm{pm}$ the same day. They might then return to work at 4.00 am the next day and repeat for six or seven days in a row.

Travelling to work in central London tends to be by public transport, with the employer discouraging workers from driving. However, it can cause stress via leaving home early to make sure to be on time due to a lack of trust in the smooth running of public transport. There were also examples of fatigued driving after a long shift (one by motorbike). It is important to note that commuting by public transport does permit workers to sleep after a shift.

Some workers had family homes far from London e.g. in Scotland, Newcastle, Durham, Portsmouth and Dublin but were unable to find work in tunnelling construction in those areas. This affected fatigue in a different way from those who lived close enough to commute every day. Those who lived away from London would return to their home base whenever their rest periods were long enough; some shift patterns may mean staying away from home for 25 days then being home for only three.

For these workers, being permitted to leave early on the last shift before a break was a welcome concession, allowing them to have a little more time with their family. However, the journey home for these workers was a source of fatigue itself, with one noting travelling on a sleeper train in order to be able to sleep before and after a shift. Some might also travel from a significant distance (including driving) then go straight to work without sleeping beforehand and might have been awake for up to 25 hours: "... doing night shift. And then finishing at six, seven o'clock in the morning, and they've been up twenty-four, twenty-five hours, twenty-six hours by the time they got home". Managers were aware of these concerns but felt unable to influence the situation.

Commuting a long distance after a series of shifts could be problematic, particularly if driving home on a Friday when there is much traffic. It was suggested that a 12-hour shift followed by a drive home of 4-5 hours is "a killer", and "not normal". Examples of feeling drowsy at the wheel were cited, with some being thankful for the rumble strips between motorway lanes.

There seemed to be inconsistency or uncertainty about the practicalities of recording and delineating shift patterns concentrated around a clear definition of the length of the shift, what it includes and when workers are being paid to be there. For example, focus groups stated having to be in attendance before the start of a shift for the purpose of being briefed. There was possibly some confusion over terminology here; the shift was usually described as being 'eight hours' (the time spent in the tunnel) but was in fact longer in order to allow for time for shift briefings and 
travelling down to the site proper. On occasions, workers seemed unclear on whether they were attending briefings in their own time or paid time.

\subsection{Work life and home life}

The results in this section include findings assigned to the following codes:

- countermeasures - outside of work to be fit for work

- individual responsibility

- other effects of shiftwork

- sleep, lack of sleep and time awake

- temporary accommodation

- work life home life

Working conditions in the tunnelling construction sector did not always correspond with the desire of the workers to spend time with their family. Unsurprisingly, the groups expressed such a wish; managers were aware of this and were understanding about it. Workers generally felt that their shift patterns, and often having to work away from their home base, lead to them having insufficient family time and a feeling that their lives revolve around work. As stated by one focus group worker: "We don't have much of a life apart from this" and being away from home and completing seven shifts may impede a social life: "If you're on permanent days you see guys at the end of the shift saying, come on, we'll go for a couple of beers before going home to our families. We don't do that in shift work. Just onto a train and head back to the digs. So, you've no social life".

Workers discussed the difficulties of balancing their work and home life, and how this could lead to feeling tired. Non-working time was often taken up with the needs of their families, causing workers to miss out on rest, relaxation and sleep time. This was also true when considering social commitments which might cause them to stay up late, therefore lacking sufficient sleep before a subsequent shift. This was particularly the case for younger workers.

Some workers reported difficulty relaxing between shifts, which may also lead them to have insufficient or poor sleep. They may also become anxious about going home and thereby experience disrupted sleep. Sleep was also affected by workers on their days off catching up on all the experiences they had missed through being away at work (drinking, eating, socialising) and which they had looked forward to all month. It was stated in more than one focus group that some shift patterns lead to only twelve weekends a year at home, which was described as being "pretty savage". This could also mean that these workers missed out on family experiences.

\subsection{Shift preferences}

The results in this section include findings assigned to the following codes:

- other effects of shiftwork

- $\quad$ shift patterns - effects of different ones

- shift patterns - times and situations that are the most fatiguing

- shift patterns - working weekends

- work life home life

It was apparent from the interviews and focus groups that the participants believed that no perfect shift pattern exists in tunnelling construction (where 24-hour working is required). There was 
general agreement that workers demonstrate lower levels of tiredness when on eight-hour shifts than when on 12-hour shifts. The managers believed that shorter (eight-hour) shifts are a positive step towards the mitigation of fatigue, with several citing the introduction of these as an industrywide improvement. However, workers often preferred 12-hour patterns due to the greater amount of family time and higher pay.

Shift patterns varied across sites and projects and also during the lifecycle of a project. Some workers preferred eight-hour shifts and others favoured 12-hour shifts; shorter shifts offered more time at home for those living nearby; 12-hour shifts meant longer and more frequent weekends off work for those whose home base is further away. Shorter weekends (i.e. a shorter time between stopping work on a Friday and beginning again on a Monday) are not appealing to those workers whose home base is further away since they are not able to go home very often, and when they do, they are likely to be very tired.

Rotating shifts led workers to feel constantly jetlagged as their circadian rhythms were continuously disturbed. A key example of this disturbance was cited as coming off nights and going into the evening shift. Workers complained that they would get accustomed to working on a specific pattern only to have to change the pattern again: "So from your whole world being a night-time world that's all going to be turned around within the space of two days and ... that's difficult for your body to do". Notably, missing just a short period of sleep at the beginning of the shift pattern could affect the rest of the week, making it difficult to catch up on that lost sleep.

\subsection{Reporting fatigue}

The results in this section include findings assigned to the following codes:

- definitions and understanding of fatigue

- expectations and culture of the industry or company

- reporting or admitting fatigue

- sickness

- team working and co-dependency

Most of the workers commented that they would be unlikely to report fatigue to a supervisor or manager or discuss it amongst themselves; this reluctance was due to social concerns (not wishing to appear ' weak') and potential disciplinary proceedings. As a result, they suggested that if they felt fatigued, they would either not attend work, or just carry on working. They noted they would not receive any pay if they were absent from work. Some workers believed they could control their work to some extent and knew when they should stop and have a break, although they did not always feel able to do so. When fatigued, they would carry on working to the end of the shift, because "... it's just, get on and get your work done. It still has to be done, so you, whether you're tired or not, it still needs to be done". This may refer to the nature of tunnelling construction where one function relies on a variety of others. It may also a view amongst some tunnellers that managers think "if you're tired, there's no excuse for it. If you [work] all the shifts in a row, and work very hard, there's no excuse to be tired". Being able to keep going when fatigued may be enabled by the repetitive nature of tunnelling in which workers are very accustomed to the task at hand. In contrast, managers suggested monotonous tasks can be a contributor to fatigue.

Although participants stated that they rarely admitted to tiredness or fatigue and would be unlikely to have conversations with each other on this subject, they felt they could, and did, recognise 
fatigue in others: they usually worked in small familiar teams in which they get to know each other well. For example there was a discussion between two participants on how the other would behave when tired: "I'd expect him either to be shouting or being grumpy or not talking ... and I presume you'd expect that of me because I'm tired". In this situation, they would help a fatigued colleague, or advise them to take a break/nap and cover for them: "If he looks as though he's tired, you go and give him a hand ...". It was noted in this respect that operating as a team means that one member experiencing fatigue can affect the remainder of the team; everyone is equal no matter where in the operation they are situated. It was also noted that workers "look out for each other".

It is noteworthy that the managers would not necessarily be aware that the tunnellers protect each other in the way described above. However, managers themselves reported protecting the men they work with regularly and taking notice of their health, especially the older workers: "... we had a couple of older guys, who'd be in their sixties ... doing a good job, so you'd sort of keep an eye on them ... we'd know quite a lot about them, their health ... we really got to know the team". This protection is a positive outcome of the small familiar teams evident in the industry and the participating managers had sufficiently detailed knowledge of their workers to state that they knew which workers to choose for particular parts of each team.

Furthermore, the managers interviewed generally wanted to create a situation in which workers feel comfortable talking about fatigue and sleepiness. Indeed, they thought that their detailed knowledge of their workers and the small teams allowed this to happen more easily. Some of the managers are therefore likely to be understanding about a worker reporting feeling fatigued and would try to find out the cause and be supportive. Managers also often believe that the team itself would pinpoint someone who was a concern and would not allow them to work in such a situation: "the person in charge wouldn't put someone to work if they weren't fit".

The research indicated that more space in which to rest at the sites would be beneficial and would allow workers to relax and sleep before shifts and during breaks. Such space could take the form of either quiet areas or designated rooms. In this context in particular, there were suggestions from the managers that there is ambiguity around how to react to workers who sleep in the canteen during their breaks, with some sympathetic to their needs, and others responding with disciplinary action.

\subsection{Safety and productivity}

The results in this section include findings assigned to the following codes:

- countermeasures - what you do at work

- definitions and understanding of fatigue

- expectations and culture of the industry or company

- other effects of shiftwork

- safety and productivity

- sleep, lack of sleep and time awake

There was a clear contrast between the focus groups and managers when considering safety and productivity. Managers generally expressed a view that fatigue can make workers unsafe for work mainly because they are less alert. It can be a danger particularly for certain roles involving the use of heavy machinery. They were concerned about safety both on site and during any extended commuting times. Conversely, many workers believed that they could simply continue working through any feelings of fatigue without impacting on safety or productivity, particularly when 
undertaking repetitive work; they generally felt this did not make them unsafe to work. However, there was some recognition that they may be less safe towards the end of a shift/series of shifts when the fatigue was at its peak (noted by workers and managers), and that if someone was tired they were not necessarily paying attention to their job and may make more mistakes. As suggested by one worker: "All you're thinking about is going home to be honest, you're not thinking about anything else other than, I can't wait to get to my bed".

\section{DISCUSSION}

This study has shown that, in common with other industries (particularly those which operate shift work), fatigue is a recognised problem for the participating tunnelling workers and their managers. Participants in both the focus groups and interviews agreed that fatigue is a concern for the industry; they have a similar level of understanding of mental and physical fatigue, and on the ways in which these manifest.

The issue of fatigue has a broad range of consequences with distinct characteristics, with all participants being aware of and discussing these. However, although widely recognised, fatigue is not yet being adequately addressed in the industry. For instance, the research suggests that currently the industry tolerates levels of fatigue risk which are very high, for example, workers being awake for $\mathbf{2 4}$ hours or longer, workers commuting two hours each way on a daily basis and workers driving when very tired.

As has been found in a wealth of other studies (see, for example, Anderson et al., 2012; Colquhon, 1976) and Folkard \& Monk, 1979), shift patterns were a key contributor to fatigue for the participants. Research involving miners working in a fly-in-fly-out operation in Australia also showed a link between shifts and fatigue (Muller et al., 2006). With general requirements in the tunnelling construction sector for 24/7 working, shifts are a necessity and the various shift patterns are having an impact on the workers. There is a balance to be struck between fatigue and wellbeing which makes it particularly difficult to implement a shift pattern which is widely acceptable. That is, there is a potential conflict between what suits workers who live with their families (shorter shifts) and what suits workers who live away from their home base (longer shifts). It is likely that fatigue will affect these two groups differently as they seek to spend time with their family and avoid feeling that their life involves just working and sleeping. Other studies involving fly-in-fly-out workers (who spend significant time away from their family) have investigated the impact of this kind of work on the family, finding that female partners are particularly affected (Pini and Mayes, 2016).

Individual differences between workers are also of importance when considering fatigue, with some people preferring particular or specific shifts and working times (e.g. constant night shifts). The debate around 12-hour shifts (compared to 8-hour ones) is discussed by Ferguson and Dawson (2012) with one of their conclusions being that key influences include "the work pattern, the worker and the work type" (p527). This is certainly true of tunnelling workers. Furthermore, general construction work has been shown to involve a poor work-life balance (Sherratt and Turner, 2018; Forberg et al., 2010) and these considerations could mitigate against this. There is agreement between tunnellers and their managers that shift patterns are a key cause of tiredness, a key difference being that managers believe that the introduction of shorter shifts is already having an effect on fatigue.

In common with other research closely related to this study (Jones et al., 2019), there was evidence of confusion over the definition of a '12-hour' shift. This has revealed the importance of consistent 
language around the length of a shift and what it includes. For example, an 'eight hour' shift might involve eight hours working at the tunnel face. However, additional time will be spent changing in and out of work clothes, attending safety briefings and travelling to and from the face (which becomes a progressively longer journey as work progresses). There appears to be inconsistency as to whether this extra time is factored in when assessing fatigue risks. This is important given the evidence that long work shifts in safety-critical operations have been associated with fatigue and increased accident risk after approximately eight to nine hours on duty (Kecklund et al., 2016). It is even more problematic where '12 hour' shifts are actually 13 or 14 -hour shifts as this has an impact on the time available for sleep.

For fatigue management to improve a change within the industry is necessary. The apparent conflict between workers who generally avoid reporting or discussing feeling fatigued and managers who believe that there is increased openness and willingness to do so is particularly concerning. Although some managers appear keen to be approachable on the subject of fatigue and to actively protect their workers from its consequences, this is either not universal or is not permeating to the frontline workers. If the industry wishes to improve its fatigue management, there is a need to ensure that any changes in company beliefs are extended across the whole organisation, ensuring a shared responsibility in this regard.

A more open environment might also be a means of resolving the differences between the tunnellers and their managers in regard to the issue of safety and productivity. With managers expressing the view that fatigue can make workers unsafe for work, it is concerning that the workers generally thought this not to be the case. One reason given by workers that fatigue was not a safety concern is because of the teamwork nature and the belief that they can compensate for a colleague's impaired performance. The negative impact of fatigue and sleepiness at an individual level is well known, including impaired performance at a range of tasks such as slowed reaction time and impaired decision making (Harrison \& Horne, 2000). Similarly, the impact of fatigue on safe operations is widely acknowledged, for example, in the rail industry it has been demonstrated that the risk of a human factors accident is elevated $11-65 \%$ above chance by exposure to fatigue (Gertler et al., 2012). However, comparatively less is known about the potential for team working to minimise the risk of fatigue (Banks et al., 2019). Future research is necessary to understand the impact of individual fatigued workers within a team setting before conclusions can be made as to whether or not team environments are effective at mitigating the impact of fatigue. In addition, many participants believed that their working performance would not be impaired by feelings of fatigue due to the repetitive nature of their work. It is notable that this was contradicted by other comments from workers (and managers) suggesting that the monotonous nature of the work itself can be a contributor to fatigue. It is commonly reported that sleep loss leads to an instability in task performance, particularly for reaction time (Doran et al., 2001). Within a repetitive task it is possible that brief lapses in attention may pass without consequence, however, because the timing of such lapses are unpredictable there is potential for occurrence during a safety critical situation which could have disastrous consequences. Tiredness amongst managers was also evident, caused by working over their allotted time to keep up with the workload and causing stress and poor decision making. Based on what is already known about fatigue the fact that workers would continue working despite being tired is of great concern.

Tunnellers and managers participating in this research all agreed that workers should have individual responsibilities for managing fatigue, that is, taking care of their sleep hygiene and managing their 
time appropriately in order to do so. There was evidence of such a recognition in workers noting that they would not attend work if feeling tired. However, there is also a need for a shared responsibility over the issue of fatigue. That is, all parties (workers, managers, senior management and clients) have a part to play in ensuring that the environment does not allow workers to become fatigued or is able to mitigate the impact if they do.

\section{LIMITATIONS}

Although this report demonstrates that fatigue is a concern in the tunnelling construction sector, there are some limitations. Firstly, the sample used in each research task may not be fully representative of all tunnelling workers. Although steps were taken to ensure that as wide a variety of tunnelling personnel as possible were able to participate in the research, the sample of participants is fairly small. However, most participants had worked on several other tunnelling construction projects, often over many years, ensuring an appropriate breadth of industry experience.

Furthermore, managers were selected based on their availability at the time of the focus groups (or soon afterwards) and this might therefore have limited the range of accessible personnel. However, the other criterion for recruitment again ensured that they brought wide experience to the research beyond this particular construction project and their experience of supervision in 24-hour tunnelling construction.

One of the focus groups involved tunnellers who had not yet begun underground working on their current project. However, all had previous (and sometimes recent) experience of tunnelling construction and $24 / 7$ shift working and so were still able to offer valid knowledge and opinions to the research.

Due to logistical problems, manager interviews included a mixture of face-to-face and telephone discussions. Although not physically present for the telephone interview, the researcher made sure that the data collection was similar in duration and detail to the face-to-face interview so that the quantity and quality of data would not be compromised.

\subsection{Areas for future focus}

This research describes the current context and provides a basis for future investigations related to fatigue concerns. It confirms that fatigue is an issue in tunnelling construction and as well as providing an understanding of the current state of affairs it will allow the stakeholders as well as the industry and other researchers to argue strongly that further research is needed. In addition, a more extensive study of tunnellers might attempt to canvas a wider range of opinions from tunnellers; this could include a questionnaire survey and further focus groups with a wider range of workers from other large tunnelling construction projects.

Key examples for future focus include the impact of commuting times, an issue which has arisen in other research and which was raised by both the focus group participants and the managers in this study. It is also suggested that the reality of fatigue could be tested using physiological measures (such as blink rate and heart rate) particularly focusing on its effect on performance in relation to the extremes in physical environment faced by tunnellers. Another opportunity for further research could focus on team working, given the comments related to this kind of work within the current study. More specifically, since workers recognise and act on fatigue in members of their team but 
believe that they can work with fatigue on their own part, a future study could investigate whether they make conscious related decisions based on the specific task being carried out at that time and the potential consequences of error.

\section{CONCLUSIONS}

In response to the research questions related to this study and expressed at the beginning of this article, it can firstly be concluded that tunnelling personnel believe fatigue/sleepiness to be a problem in their sector. Fatigue is a psychological and/or physical impairment experienced by a worker (either subjectively or objectively) which has the potential to reduce optimal performance; this was clear in this research concentrating on tunnelling sector workers. We can conclude from this research that fatigue in the industry is multifaceted, taking in pressures both from sleepiness and task-related fatigue. For workers in the tunnelling construction sector, fatigue may be due to sleepiness due to insufficient sleep and/or time of day, including circadian pressures all people suffer from, and the added pressures resulting from shift work. Fatigue for these workers may also be taskrelated, due to the nature of tunnelling and allied work carried out in a very particular physical environment (a tunnel) resulting in an inability to continue, or impairment in performance caused by: time on task due to the same activity going on too long; an overload of cognitive demands during times of exposure to demanding workload; or an underload of cognitive demands during times of monotonous activity and physical muscle fatigue due to physical exertion, for example, manual digging.

The second research question related to the causes and consequences of fatigue/sleepiness in the tunnelling sector; the contributors were several and included aspects focussing on shift work in general and the fact that it can lead to an inability to sleep and to the physical aspects of the tunnelling sector. The consequences for the study participants were found to be concentrated around safety in the workplace (with varying opinions on whether fatigue has negligible or negative effects on safety) and its influence on the home life of workers.

The third research question addressed how fatigue is being managed in the tunnelling sector. Overall the research suggested that the sites involved in the research are not yet addressing the issue of fatigue adequately, but that there is opportunity for the construction industry in general to improve fatigue management. This will require a shift within organisations and a multi-stranded approach. The organisational approach to fatigue is a central issue in its management and it is unlikely that changes will be made unless this is addressed. An incentive for the construction industry might be the fact that it is associated with a high number of accidents (35\% to $40 \%$ of fatalities while employing less than $10 \%$ of the total workforce in industrialised countries) and typically involves physically demanding tasks often performed in difficult environmental conditions which can cause fatigue and lead to poor judgment, poor quality of work, increased risk of accidents and reduction in productivity (Aryal et al., 2017).

The original contribution of this work is argued to be focused around the general construction industry rather than within the more general topic of research into fatigue and some similarities with other industrial fields have been highlighted in this article. There are differences between tunnelling construction and both general construction and mining. In the case of general construction, almost all other non-tunnelling activities by nature do not operate on a 24/7 basis. Therefore, 24/7 shifts are not essential for non-tunnelling work and tend to be used only in specific circumstances and usually for a short period of time. The widespread use of $24 / 7$ working in 
tunnelling construction makes the study of the effects of fatigue on the workers particularly relevant; this can also be seen in Pilkington-Cheney et al. (2020).

An original contribution of this work with regard to fatigue is the unusual finding of workers denying that work when sleepy is a safety concern. The justification given for this opinion by workers was the team-based nature of the work, although a similar perspective of teamwork being protective of fatigue was not reported by managers. Future research is needed to examine the validity of these perspectives.

\section{Acknowledgements}

The authors would like to thank the participants for their time and contributions. This research was funded by Tideway who have given permission for the publication of this article. The contribution to the analysis of data related to this research of Fran Pilkington-Cheney and Nathan Stuttard is also gratefully acknowledged.

\section{References}

Anderson, C., Sullivan, J. P., Flynn-Evans, E. E., Cade, B. E., Czeisler, C. A., \& Lockley, S. W. (2012) Deterioration of neurobehavioral performance in resident physicians during repeated exposure to extended duration work shifts. Sleep, 35 (8), 1137-1146. DOI: https://doi.org/10.5665/sleep.2004

Anund, A., Fors, C., Ihlström, J., \& Kecklund, G. (2018) An on-road study of sleepiness in split shifts among city bus drivers. Accident Analysis \& Prevention, 114, 71-76. DOI:

https://doi.org/10.1016/j.aap.2017.05.005

Aryal, A., Ghahramani, A., \& Becerik-Gerber, B. (2017) Monitoring fatigue in construction workers using physiological measurements. Automation in Construction, 82, 154-165. DOI:

10.1016/j.autcon.2017.03.003

Banks, S., Landon, L. B., Dorrian, J., Waggoner, L. B., Centofanti, S. A., Roma, P. G., \& Van Dongen, H. P. (2019) Effects of Fatigue on Teams and Their Role in 24/7 Operations. Sleep medicine reviews, 101216. DOI: https://doi.org/10.1016/j.smrv.2019.101216

Bartley, S.H. \& Chute, E. (1947) Fatigue and impairment in man. McGraw-Hill Book Company.

Boschman, J.S., van der Molen, H.F., Sluiter, J.K., \& Frings-Dresen, M.H.W. (2013) Psychosocial work environment and mental health among construction workers. Applied Ergonomics, 44, 748-755. DOI: https://doi.org/10.1016/j.apergo.2013.01.004

Bowen, P., Govender, R., Edwards, P., \& Cattell, K. (2018). Work-related contact, work-family conflict, psychological distress and sleep problems experienced by construction professionals: An integrated explanatory model. Construction Management and Economics, 36 (3), 153-174. DOI: 10.1080/01446193.2017.1341638

Bustamante, A.Z. (2016) Understanding fatigue and sleep behaviours of the shift pattern 7-4-7-3 (seven days/four days off/seven nights/three days off) within Transport for London and Crossrail construction/tunnelling projects. Unpublished MSc dissertation from Middlesex University.

Chang, F., Sun, Y., Chuang, K. \& Hsu, D. (2009) Work fatigue and physiological symptoms in different occupations of high-elevation construction workers. Applied Ergonomics, 40, 591-596. DOI: https://doi.org/10.1016/j.apergo.2008.04.017 
Colquhoun, W.P. (1976) Accidents, injuries and shift work. In P.G. Rentos \& R.D. Shepard (Eds), Shift Work and Health (76-203). Washington DC: US HEW Publishing

Dawson, D., Searle, A.K. \& Paterson, J.L. (2014) Look before you (s)leep: Evaluating the use of fatigue detection technologies within a fatigue risk management system for the road transport industry. Sleep Medicine Reviews, 18, 141-152.

Dement, W.C. \& Carskadon, M.A. (1982) Current perspectives on daytime sleepiness: the issues. Journal of Sleep Research \& Sleep Medicine, 5(Suppl 2): 56-66.

Dong, X. (2005). Long workhours, work scheduling and work-related injuries among construction workers in the United States. Scandinavian Journal of Work, Environment \& Health, 31 (5), 329-335. DOI: 10.5271/sjweh.915

Doran, S. M., Van Dongen, H. P. A., \& Dinges, D. F. (2001) Sustained attention performance during sleep deprivation: evidence of state instability. Archives italiennes de biologie, 139 (3), 253-267.

Ferguson, S.A. \& Dawson, D. (2012) 12-h or 8-h shifts? It depends. Sleep Medicine Reviews, 16, 519528.

Filtness, A.J. \& Naweed, A. (2017) Causes, consequences and countermeasures to driver fatigue in the rail industry: The train driver perspective. Applied Ergonomics, 60, 12-21. DOI: https://doi.org/10.1016/j.apergo.2016.10.009

Folkard, S., \& Monk, T. H. (1979). Shiftwork and performance. Human factors, 21 (4), 483-492. DOI: https://doi.org/10.1177/001872087902100410

Forberg, K., Waage, S., Moen, B. \& Bjorvatn, B. (2010) Subjective and objective sleep and sleepiness among tunnel workers in an extreme and isolated environment: 10-h shifts, 21-day working period, at 78 degrees north. Sleep Medicine, 11, 185-190. DOI: https://doi.org/10.1016/j.sleep.2009.07.015

Francis, T. J. R., \& Mitchell, S. J. (2003). Manifestations of decompression disorders. Bennett and Elliott's physiology and medicine of diving. 5th ed. London: Saunders, 578-599

Gander, P., Hartley, L., Powell, D., Cabon, P., Hitchcock, E., Mills, A. \& Popkin, S., (2011) Fatigue risk management: Organizational factors at the regulatory and industry/company level. Accident Analysis \& Prevention, 43 (2), 573-590. DOI: https://doi.org/10.1016/j.aap.2009.11.007

Gertler, J., DiFiore, A., \& Raslear, T. (2012) Fatigue Status of the US Railroad Industry (Tech. Rep. DOT/FRA/ORD-13/06). US Department of Transportation, Washington, DC: Federal Railroad Administration.

Halvani, G.H., Zare, M. \& Mirmohammadi, S.J. (2009) The Relation between Shift Work, Sleepiness, Fatigue and Accidents in Iranian Industrial Mining Group Workers. Industrial Health, 47 (2) 134-138. DOI: https://doi.org/10.2486/indhealth.47.134

Harrison, Y., \& Horne, J. A. (2000) The impact of sleep deprivation on decision making: a review. Journal of experimental psychology: Applied, 6 (3), 236.

Holguín-Veras, J., Ozbay, K., Baker, R., Sackey, D., Medina, A., \& Hussain, S. (2003). Toward a comprehensive policy of nighttime construction work. Transportation Research Record, 1861(1), 117-124. DOI: 10.3141/1861-12 
Jackson, J. E., Sanquist, T., Campbell, J., Lee, E. B., \& Van Dongen, H. P. (2013). Fatigue in highway construction workers: risks and countermeasures in rapid renewal project schedules. Transportation Research Record, 2347(1), 11-18. DOI: 10.3141/2347-02

Johns, M.W. (1991) A New Method for Measuring Daytime Sleepiness: The Epworth Sleepiness Scale. Sleep, 14 (6), 540-545. DOI: 10.1093/sleep/14.6.540

Jones, W., Filtness, A., Haslam, R., Gibb, A. \& Stuttard, N. (2019) Waking up to fatigue. Tunnelling Journal, June/July, 28-31.

Karkoulias, K., Lykouras, D., Patouchas, D., Sargianou, M., Sampsonas, F., Faliagka, E., Tsakalidis, A. \& Spiropoulos, K. (2012). Study of daytime sleepiness among tunnel workers on rotating schedule.

European Respiratory Journal, 40:P4011. Available at:

https://erj.ersjournals.com/content/40/Suppl_56/P4011

Kecklund, G., Sallinen, M. \& Axelsson, J. (2016) Optimizing Shift Scheduling. In: Kryger, M., Roth, T. \& Dement, W. (Eds). Principles and Practice of Sleep Medicine, 742-751.

Killgore, W. D. (2010). Effects of sleep deprivation on cognition. Progress in brain research, 185, 105129. DOI: https://doi.org/10.1016/B978-0-444-53702-7.00007-5

Ku, C.H \& Smith, M.J. (2010) Organisational factors and scheduling in locomotive engineers and conductors: Effects on fatigue, health and social well-being. Applied Ergonomics, 41 (1), 62-71. DOI: https://doi.org/10.1016/j.apergo.2009.04.006

Kumar, K., \& Chaturvedi, R. (2018). Women in construction industry: A work-life balance perspective. International Journal of Civil Engineering and Technology (IJCIET), 9(08), 823-829.

Lingard, H. and Turner, M., 2017. Promoting construction workers' health: a multi-level system perspective. Construction Management and Economics, 35(5), pp.239-253.

Lykouras, D., Karkoulias, K., Patouchas, D., Lakoumentas, J., Sampsonas, F., Tranou, M. K., Faliagka, E., Tsakalidis, A. \& Spiropoulos, K. (2014). Experience and limited lighting may affect sleepiness of tunnel workers. BMC Research Notes, 7(1), 417. DOI: 10.1186/1756-0500-7-417

Maiti, R. (2007) Workload assessment in building construction related activities in India. Applied Ergonomics, 39, 754-765. DOI: 10.1016/j.apergo.2007.11.010

Maman, Z.S., Yazdi, M.A.A, Cavuoti, L.A. \& Megahed, F.M. (2017) A data-driven approach to modeling physical fatigue in the workplace using wearable sensors. Applied Ergonomics, 65, 515529. DOI: 10.1016/j.apergo.2017.02.001

Muller, R., Carter, A. \& Williamson, A. (2008) Epidemiological Diagnosis of Occupational Fatigue in a Fly-In-Fly-Out Operation of the Mineral Industry. The Annals of Occupational Hygiene, 52, 63-72. DOI: https://doi.org/10.1093/annhyg/mem058

Paech, G.M., Jay, S.M., Lamond, G.D.R. \& Ferguson, S.A. (2010) The effects of different roster schedules on sleep in miners. Applied Ergonomics, 41, 600-606. DOI:

https://doi.org/10.1016/j.apergo.2009.12.017

Pilkington-Cheney, F., Filtness, A., Jones, W., Maynard, S., Gibb, A. \& Haslam, R. (2020) Biomathematical modelling for managing worker fatigue in civil engineering. Proceedings of the 
Institution of Civil Engineers - Civil Engineering. DOI: https://doi.org/10.1680/jcien.20.00009. Accepted 14.03.20.

Pini, B. \& Mayes, R. (2016) Gender, emotions and fly-in-fly-out work. Australian Journal of Social Issues, 47 (1), 71-86. DOI: https://doi.org/10.1002/j.1839-4655.2012.tb00235.x

Saldana, J. (2009) An introduction to codes and coding. The Coding Manual for Qualitative Researchers. London, UK: Sage.

Sherratt, F. \& Turner, M. (2018) Exploring the hidden social consequences of working in construction with Q Methodology: Developing a study for Australia and the UK. Proceedings of the Joint CIB W099 and TG59 Conference. Coping with the Complexity of Safety, Health and Wellbeing in Construction. Salvador, Brazin, 1-3 August 2018.

Whitney, P., Hinson, J. M., Jackson, M. L., \& Van Dongen, H. P. (2015). Feedback blunting: total sleep deprivation impairs decision making that requires updating based on feedback. Sleep, 38 (5), 745754. DOI: https://doi.org/10.5665/sleep.4668

Zhang, M., Murphy, L. A., Fang, D. \& Caban-Martinez, A. J. (2015) Influence of fatigue on construction workers' physical and cognitive function. Occupational Medicine, 65 (3), 245-250. DOI: https://doi.org/10.1093/occmed/kqu215 